\section{China: change tack to boost basic research}

We agree that China must invest more in basic research, but fear that simply casting more seeds on infertile ground will not yield the anticipated fruit of innovation (W. Yang Nature 534, 467-469; 2016). More bottom-up initiatives for early-career researchers are required for long-lasting change.

A priority is to build capacity in critical thinking and selfdetermination, both of which are cornerstones of creative enquiry. Early-career scientists should be trained and judged on more than just technical competence. Furthermore, strategies are needed to give young researchers in China the same opportunities that leading Western institutions take for granted. Limited access to key information services and an educational emphasis on written knowledge over verbal communication skills do not foster scientific debate.

Structural reform of funding silos and hierarchical power structures in science institutions is essential for cross-sector collaboration - a crucial contributor to scientific progress in Western countries. Chinese funding schemes such as the 10,000 Talents programme could be redistributed across an evenedout power structure, and associate professors allowed to supervise PhDs and lead their own groups.

The applied-research sector receives much more funding than basic science does (see Nature 534, 452-453; 2016), so it could help by promoting the possible benefits of its work for basic research in reports and funding applications.

Raphael K. Didham, Chao-Dong Zhu Institute of Zoology, Chinese Academy of Sciences, Beijing, China. zhucd@ioz.ac.cn

\section{China: standardize R\&D costing}

Figures for China's basic-research spending should not be taken at face value (see W. Yang Nature
534, 467-469; 2016). Before comparing gross expenditure on research and development (R\&D) with that in developed countries, China's official statistics first need bringing into line with international standards for collecting and reporting $\mathrm{R} \& \mathrm{D}$ costs (see go.nature. com/2ab54rh).

Unlike most other countries, China's government has no official system for assessing R\&D expenditure. These costs are instead embedded in the overall costs for science and technology (see Y. Sun and C. Cao Science 345, 1006-1008; 2014). And China's R\&D statistics exclude salaries for university faculty members and postdocs - a significant component of R\&D expenditure in other countries. Capital spending on big facilities and their operation budgets, known as fixed R\&D costs in many Western countries, are not counted. For instance, only about US $\$ 18$ million of the $\$ 200$ million spent on the first construction phase of the Shanghai Synchrotron Radiation Facility was designated as an $\mathrm{R} \& \mathrm{D}$ cost (see go.nature. com/2alwvbc).

Based on such considerations, China probably spent about double the official figure of $4.7 \%$ of its total R\&D budget on basic research in 2013, as quoted by Yang. This is still significantly less than Japan or the United States.

Yutao Sun Dalian University of Technology, China.

Cong Cao The University of Nottingham Ningbo, China. sunyutao82@dlut.edu.cn

\section{Mentoring female scientists in Africa}

As founding members of the Higher Institute for Growth in Health Research (HIGHER) for Women in Cameroon, our mission has been to help young women to enter and sustain careers in biomedical science through a mentoring programme (www.higherwomencam.org).

Mentored female researchers spend more time on research and have more publications and greater career satisfaction than do their unmentored peers (W. Levinson et al. West J. Med. 154, 423-426; 1991). In disadvantaged settings such as Cameroon, however, potential female mentors are in short supply.

Led by one of us (R. G. F. L.) and funded by the Special Programme for Research and Training in Tropical Diseases and Canada's International Development Research Centre, the HIGHER Women consortium has recruited more than 100 members in the past year. Its 20 or so mentors hold leading positions in Cameroon in academic institutions, research organizations or government agencies; each has four or five mentees on average.

The consortium follows a holistic approach, taking into account the pressures on women in a traditional culture and encouraging career-life balance through planning and coordination. It is developing scientists' skills in grant writing, leadership, ethics, research quality and time management. Rose G. F. Leke, S. Kwedi Nolna University of Yaoundé, Cameroon. roseleke@yahoo.com

\section{Refereed science to guide action on EDCs}

In a non-peer-reviewed venue (Nature 535, 355; 2016), Daniel Dietrich et al. put forward apparently unsubstantiated arguments that in effect dismiss thousands of peer-reviewed academic studies and rigorous evaluations of endocrinedisrupting chemicals (EDCs) by independent scientists and organizations such as the World Health Organization (WHO), the United Nations Environment Programme, the Endocrine Society and the International Federation of
Gynecology and Obstetrics (see, for example, go.nature. com/2adgma2).

Identification of hazards associated with EDCs relies on randomized mechanistic studies in animals and observational epidemiological studies in humans. Randomized trials of direct chemical exposures in humans present serious ethical and other challenges. Using approaches developed by the WHO and the Intergovernmental Panel on Climate Change to account for the totality of the laboratory and human evidence and assess the strength of the evidence, the costs of continued inaction on EDCs are estimated to be more than $€ 150$ billion (US $\$ 167$ billion) annually (L. Trasande et al. J. Clin. Endocrinol. Metab. 100, 1245-1255; 2015).

Proactive prevention measures backed by strong scientific criteria are therefore needed to prevent disease and disability across the life course. Regulatory decision-making should rely on peer-reviewed research to evaluate EDCs (L. Trasande et al. J. Epidemiol. Comm. Health http://doi.org/bm5q; 2016). Many of us have productively worked to achieve scientific consensus for the proposed criteria for EDCs in Europe (see go.nature.com/2awvrsn). In our view, Dietrich et al. do nothing to advance the debate or scientific knowledge on this important human health issue.

Leonardo Trasande NYU School of Medicine, New York City, USA. leonardo.trasande@nyumc.org Supported by 25 signatories (see go.nature.com/2aotwpifor full list).

\section{CORRECTION}

The print version of the Correspondence by M.W. Hayward et al. (Nature 534, 475; 2016) incorrectly stated that 16 rhinos will be moved from Africa to Australia this year; in fact, it will be 6 . 